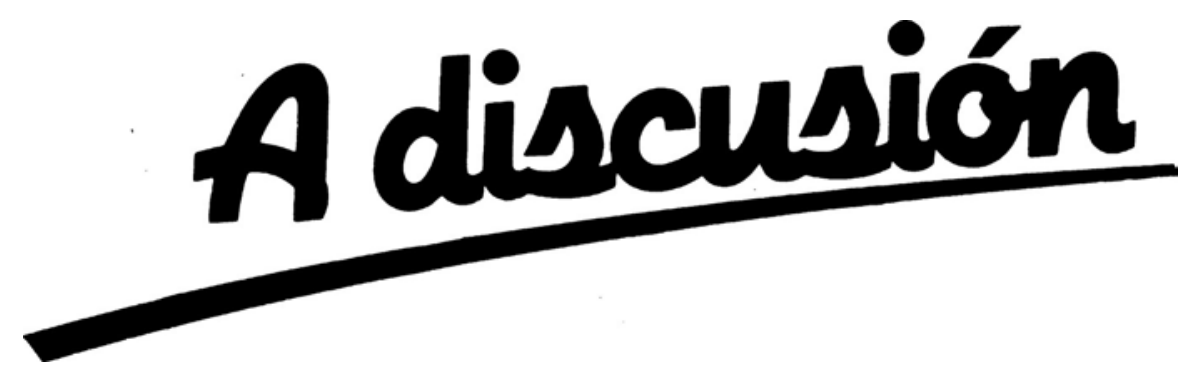

\author{
ON THE PRICE OF RECREATION GOODS \\ AS A DETERMINANT OF MALE LABOR SUPPLY*
}

Jorge González-Chapela**

WP-AD 2007-04

Editor: Instituto Valenciano de Investigaciones Económicas, S.A.

Primera Edición Febrero 2007

Depósito Legal: V-999-2007

IVIE working papers offer in advance the results of economic research under way in order to encourage a discussion process before sending them to scientific journals for their final publication.

\footnotetext{
* This paper is a revised version of chapter 1 of my Universitat Pompeu Fabra dissertation. I have benefited from the comments of A. Bisin, A. Ciccone, J. Galí, J. García, J. I. García, L. González, M. Güell, A. Kugler, A. López, and S. Rendón. I would also like to thank participants in seminars at Mannheim Institute for the Economics of Aging, Universidad Pablo de Olavide, Universidade de Santiago de Compostela, and Universitat Pompeu Fabra. My deepest gratitude to K. T. Reilly, X. Sala-i-Martin, and E. Villanueva for ideas, support, and criticism. The author gratefully acknowledges support from the European Union (HPRN-CT-2002-00235).

** Department of Economics, University of Alicante, Campus San Vicente del Raspeig, E-03080 Alicante, Spain, E-mail: jorge@merlin.fae.ua.es.
} 


\title{
ON THE PRICE OF RECREATION GOODS AS A DETERMINANT OF MALE LABOR SUPPLY \\ Jorge González-Chapela
}

\begin{abstract}
This paper examines whether and how changes in the price of goods consumed in conjunction with leisure time influence the life-cycle allocation of work effort by part of prime-age males. For the U.S., individual-level data is combined with Metropolitan Area-level price indices of recreation goods to estimate the male elasticity of intertemporal substitution of market time with respect to the price of recreation goods, which is found to be centered at 0.18 and statistically different from zero. The allocation of work effort over the life-cycle in response to changes in the price of recreation goods creates movements in the output of an economy that could be important for understanding economic fluctuations.
\end{abstract}

Keywords: Intertemporal substitution, male labor supply, panel data. 


\section{Introduction}

This paper examines whether and how changes in the price of goods consumed in conjunction with leisure time influence the life-cycle allocation of work effort by part of prime-age males. The estimation of life-cycle labor supply models in which goods and leisure time are assumed to be non-separable within the period was an active area of research in the 1980s. ${ }^{1}$ Most of the evidence accumulated by this literature did not reject the contemporaneous separability between time and goods in the individual's preference ordering. Nevertheless, this kind of separability was usually rejected by other studies using a static framework of analysis. ${ }^{2}$ To ascertain whether there exists a causal link between the price of goods and the intensive margin of labor supply is relevant: if individuals allocate work effort over the life-cycle in response to changes in the price of goods, it would create movements in the output of an economy that, depending on how prices evolve, could be important for understanding economic fluctuations. The conclusion from life-cycle models regarding contemporaneous separability is here examined.

Previous life-cycle studies focused on the influence of changes in the price of an aggregate of goods and services on the intertemporal allocation of work effort. The evidence from static models, however, points out that changes in the price of different types of goods and services generate opposing effects regarding the allocation of time: Abbot and Ashenfelter (1976), e.g., report that housing, transportation, and other services tend to be complementary with leisure time, while durables tend to be substitutable. Therefore, although the aggregate appears as not influencing the life-cycle allocation of work effort, there might be hidden very significant responses with respect to changes in the price of some types of goods. What types of goods? Using data from the American Time Use Survey, Hamermesh, Frazis, and Stewart (forthcoming) report that an average American devotes around four and a half hours per day to "socializing, relaxing, and leisure", the second most time consuming daily activity. On the other hand, Gronau and Hamermesh (2003) show that what they call "leisure" is the activity - apart from "sleep" - in which more time is combined with every dollar spent in goods consumed in the course of the activity. Thus, changes in the price of recreation goods could entail - by modifying their quantity demandedsignificant alterations in the amount of time devoted to enjoy recreation and, given the importance of this time-use category in the individual's time budget, could notably influence the allocation of time to other pursuits like market work.

To understand the effect of changes in the price of recreation goods on the intensive margin of labor supply, the next section presents a life-cycle theoretical model in which leisure time and recreation goods are assumed to be contemporaneously nonseparable. Section 3 outlines the data utilized to estimate the elasticities of intertem-

\footnotetext{
${ }^{1}$ Including in these studies are Browning, Deaton, and Irish (1985), Mankiw, Rotemberg, and Summers (1985), and Altonji and Ham (1990).

${ }^{2}$ See, for instance, Abbot and Ashenfelter (1976) and Browning and Meghir (1991).
} 
poral substitution of market time with respect to both the price of recreation goods and the price of leisure time predicted by the theoretical model for the population of prime-age males. We combine individual-level data supplied by the Panel Study of Income Dynamics with price indices of recreation goods for 27 U.S. Metropolitan Areas. The estimation approach, a generalized method of moments procedure applied over different specifications of the intertemporal labor supply equation, is discussed in Section 4. Section 5 presents the main results. The estimated elasticities of intertemporal substitution of market time with respect to the price of recreation goods and the price of leisure time center around 0.18 and 0.24, respectively. Such magnitudes imply that, for a prime-age male working two thousand hours a year, an increase of $1 \%$ in the price of recreation goods will entail three and a half annual hours more of market work, while an increase of $1 \%$ in the price of leisure time will cause him to work near five annual hours more. A final section summarizes the main conclusions of this article.

\section{Theoretical Model}

The individual's well-being depends on the consumption of recreation goods $(X)$, leisure time $(L)$, and a composite commodity representing other consumption goods $\left(C^{*}\right)$. His lifetime preference ordering is assumed to be strongly separable over periods of time, while within-period preferences are represented by the twice differentiable, strictly concave utility function ${ }^{3}$

$$
U\left(C_{t}^{*}, X_{t}, L_{t}\right)=\frac{C_{t}^{* 1-\frac{1}{\theta}}-1}{1-\frac{1}{\theta}}+\psi_{t}\left[\frac{1}{1-\frac{1}{\gamma}}\left(X_{t}^{1-\frac{1}{\rho}}+\alpha_{t} L_{t}^{1-\frac{1}{\rho}}\right)^{\frac{1-\frac{1}{\gamma}}{1-\frac{1}{\rho}}}\right]
$$

Recreation goods and leisure time are conceived as inputs to the enjoyment of recreation, which is assumed to be additively separable from other consumption goods. The parameters $\theta, \gamma$, and $\rho$-which are assumed to be strictly positive - represent the elasticity at which $C^{*}$ is intertemporally substituted, the elasticity of intertemporal substitution of the whole recreation activity, and the elasticity of contemporaneous substitution between $X$ and $L$ in the production of recreation, respectively. The time varying variables $\psi_{t}$ and $\alpha_{t}$ measure the relative importance given by the individual to the enjoyment of recreation along the lifetime and the relative importance of leisure time in the production of recreation.

\footnotetext{
${ }^{3}$ The features of this preference representation are described at length in Auerbach and Kotlikoff (1987), for instance.
} 
The individual's optimization problem in the case of perfect certainty is ${ }^{4}$

$$
\max \sum_{t=0}^{T} \frac{1}{(1+\delta)^{t}}\left(\frac{C_{t}^{* 1-\frac{1}{\theta}}-1}{1-\frac{1}{\theta}}+\psi_{t}\left[\frac{1}{1-\frac{1}{\gamma}}\left(X_{t}^{1-\frac{1}{\rho}}+\alpha_{t} L_{t}^{1-\frac{1}{\rho}}\right)^{\frac{1-\frac{1}{\gamma}}{1-\frac{1}{\rho}}}\right]\right)
$$

subject to

$$
\begin{aligned}
\sum_{t=0}^{T} R_{t}\left(C_{t}^{*}+P_{t} X_{t}+W_{t}^{*} L_{t}\right) & =\sum_{t=0}^{T} R_{t} W_{t}^{*}+A_{0}, \\
C_{t}^{*}, X_{t}, L_{t} \geq 0, \quad t & =0, \ldots, T,
\end{aligned}
$$

and

$$
A_{T+1} \geq 0
$$

where $\delta>0$ stands for the rate of time preference. In Eq. (2.2), the intertemporal budget constraint expressed in terms of other consumption goods, real wealth available at the beginning of the planning horizon is represented by $A_{0}$. Every period the individual disposes of one unit of time that is devoted to either market activities or to the enjoyment of recreation activities. Labor services are rewarded at a real rate given by $W^{*}$, assumed exogenous to the individual. To purchase one unit of $C^{*}$, one unit of real resources is needed, while to purchase one unit of $X, P$ units are necessary. $R_{t}$ is the standard discount factor.

Assuming an interior optimum, the optimality conditions are characterized by Eq. (2.2) and the next set of first order conditions:

$$
\begin{aligned}
\frac{1}{(1+\delta)^{t}} C_{t}^{* \frac{-1}{\theta}} & =\lambda R_{t}, \\
\frac{1}{(1+\delta)^{t}} \psi_{t} \Omega_{t} X_{t}^{\frac{-1}{\rho}} & =\lambda R_{t} P_{t}
\end{aligned}
$$

and

$$
\frac{1}{(1+\delta)^{t}} \psi_{t} \Omega_{t} \alpha_{t} L_{t}^{\frac{-1}{\rho}}=\lambda R_{t} W_{t}^{*}
$$

where

$$
\Omega_{t} \equiv\left(X_{t}^{1-\frac{1}{\rho}}+\alpha_{t} L_{t}^{1-\frac{1}{\rho}}\right)^{\frac{\frac{1}{\rho}-\frac{1}{\gamma}}{1-\frac{1}{\rho}}}
$$

and $\lambda$ is the marginal utility of wealth. Eqs. (3.2) and (3.3) provide a contemporaneous equilibrium relationship between recreation goods and leisure time:

$$
X_{t}=\left(\frac{W_{t}^{*}}{P_{t} \alpha_{t}}\right)^{\rho} L_{t}
$$

\footnotetext{
${ }^{4}$ The assumption of perfect certainty is not crucial and simplifies the model. Nevertheless, for comprehensive purposes, the theoretical model under uncertainty and the estimation of the intertemporal labor supply function derived from it are discussed in Appendix C. All appendices are available from the author.
} 
Substituting Eq. (5) into Eq. (3.2), and given that the unit of time available every period has to be splitted up into market time $\left(N^{*}\right)$ and leisure time, the intertemporal labor supply function is

$$
N_{t}^{*}=1-\psi_{t}^{\gamma}\left(\frac{W_{t}^{*}}{\alpha_{t}}\right)^{-\rho}\left(P_{t}^{1-\rho}+\alpha_{t}^{\rho} W_{t}^{* 1-\rho}\right)^{\frac{\rho-\gamma}{1-\rho}}\left(\lambda(1+\delta)^{t} R_{t}\right)^{-\gamma} .
$$

The elasticities of intertemporal substitution (EIS) of market time with respect to the price of leisure time and with respect to the price of recreation goods are

$$
\left.\frac{W_{t}^{*}}{N_{t}^{*}} \frac{\partial N_{t}^{*}}{\partial W_{t}^{*}}\right|_{\lambda \text { const }} \equiv \frac{\left(1-N_{t}^{*}\right)}{N_{t}^{*}}\left(\zeta_{t} \gamma+\left(1-\zeta_{t}\right) \rho\right)>0
$$

and

where

$$
\left.\frac{P_{t}}{N_{t}^{*}} \frac{\partial N_{t}^{*}}{\partial P_{t}}\right|_{\lambda \text { const }} \equiv \frac{\left(1-N_{t}^{*}\right)}{N_{t}^{*}}\left(\left(1-\zeta_{t}\right)(\gamma-\rho)\right) \gtrless 0
$$

$$
\zeta_{t} \equiv \frac{\alpha_{t}^{\rho} W_{t}^{* 1-\rho}}{P_{t}^{1-\rho}+\alpha_{t}^{\rho} W_{t}^{* 1-\rho}} \in(0,1)
$$

is - roughly - the share of the cost of leisure time in the total cost of recreation. As is well known in the literature on intertemporal substitution of labor supply, the EIS of market time with respect to the price of leisure time is positive, meaning that in periods where the wage rate is relatively high the individual increases his market time. ${ }^{5}$ Two margins of substitution contribute to this effect: on one hand, the individual reduces the amount of recreation consumed because one of its inputs is relatively expensive; on the other hand, he consumes recreation activities more intensive in recreation goods, freeing up time that is devoted to market activities. In expression (7), the former margin of substitution is represented by $\gamma$, the rate at which recreation may be intertemporally substituted, while the latter margin is captured by $\rho$, the rate at which $X$ and $L$ may be contemporaneously substituted in the production of recreation.

The sign of the EIS of market time with respect to the price of recreation goods can not be determined a priori. In periods where the price of recreation goods is relatively high, the individual reduces the amount of recreation consumed since, again, one of its inputs is relatively expensive. For the same reason, however, the individual has an incentive to rise the time intensity of the recreation activities consumed, reducing, as a consequence, the time available to be supplied to the market. In expression (8), both margins of substitution are captured - respectively - by the term $(\gamma-\rho)$. Therefore, even when $X$ and $L$ were not contemporaneously separable in the preference ordering, i.e., even when $\zeta_{t}<1$, if $\gamma=\rho$ the life-cycle allocation of work effort would be - as a matter of fact-not influenced by anticipated changes in the price of recreation

\footnotetext{
${ }^{5}$ See, for instance, Ghez and Becker (1975). Blundell and MaCurdy (1999) provide a summary of this extensive literature.
} 
goods. Hence, a non-zero EIS of market time with respect to the price of recreation goods is sufficient to reject the separability between recreation goods and leisure time, although it is not necessary.

Finally, by making use of Eq. (3.1), the intertemporal labor supply function could be alternatively written as

$$
N_{t}^{*}=1-\psi_{t}^{\gamma}\left(\frac{W_{t}^{*}}{\alpha_{t}}\right)^{-\rho}\left(P_{t}^{1-\rho}+\alpha_{t}^{\rho} W_{t}^{* 1-\rho}\right)^{\frac{\rho-\gamma}{1-\rho}} C_{t}^{* \frac{\gamma}{\theta}}
$$

The insight under this alternative specification is that, since current expenditures in other consumption goods are chosen taking into account prices and tastes in all time periods, $C^{*}$ would have the same role as $\lambda$ in Eq. (6). The estimation of Eq. (10) was pioneered by Altonji (1986), who proxied $C^{*}$ with data on food expenditures, and it has been more recently pursued by Ham and Reilly (2002), for instance. Both specifications will be estimated in the empirical part of this paper.

\section{Data}

To estimate the elasticities of intertemporal substitution (EIS) for the population of prime-age males, we combine individual-level data supplied by the University of Michigan Panel Study of Income Dynamics (PSID) with Metropolitan Area-level price indices supplied by the U.S. Bureau of Labor Statistics (BLS). Individuals surveyed by the PSID are asked the Metropolitan Area of residence and the number of market hours during the calendar year previous to the year of the interview. Besides, two measures of the price of leisure time are also available: the first $(W)$ is calculated as real annual earnings divided by annual market hours, while the second $(\varpi)$ stems from a direct question about the straight-time hourly wage which is asked of those workers who are paid on an hourly basis. We use waves 9 through 26 of the PSID for the calendar years 1976 to $1993 .{ }^{6}$ Included in our sample are male heads of PSID families between the ages of 25 and 60 . To the restrictions on hours and wage growth used by Altonji (1986), we add a geographic selection criterion, since only observations of individuals residing in Metropolitan Areas with available price indices are included in the analysis. After deleting missing values, we have an unbalanced sample with 3,742 individuals reporting an average of 6.0 observations to the sample.

As part of the Consumer Price Index-All Urban Consumers, the BLS publishes the price index of a category of goods labeled as "Entertainment", which includes the items appearing in Figure $1 .^{7}$ Starting from 1976, the series for this index are available

\footnotetext{
${ }^{6}$ The price indices used in this study are available starting from 1976, and we utilize PSID Public Release II data. The Data Appendix outlines our sample selection process and provides descriptive statistics on key variables.

${ }^{7}$ The proportion of consumer expenditures absorbed for this category of goods in the U.S. during the eighties and part of the nineties was around 7\% (see Nelson [2001]).
} 


\begin{tabular}{cl}
\hline \multicolumn{1}{c}{ Entertainment goods } & \multicolumn{1}{c}{\begin{tabular}{c}
\multicolumn{1}{c}{ Entertainment services } \\
Reading materials
\end{tabular}} \\
-Newspapers & Club memberships \\
-Magazines, periodicals, and books & $\begin{array}{l}\text { Fees for participant sports, excl. club memberships } \\
\text { Admissions }\end{array}$ \\
Sporting goods and equipment & Fees for lessons or instructions \\
-Sport vehicles, including bicycles & Other entertainment services \\
-Other sporting goods & \\
Toys, hobbies, and other entertainment & \\
-Toys, hobbies, and music equipment & \\
-Photographic supplies and equipment & \\
-Pet supplies and expense & \\
\hline \hline
\end{tabular}

Source: U.S. Bureau of Labor Statistics. CPI-All Urban Consumers.

FIGURE 2-U.S. METROPOLITAN AREAS WITH AVAILABLE “ENTERTAINMENT” PRICE INDEX, BY REGION

\begin{tabular}{ll}
\hline \hline NORTHEAST: & NORTHCENTRAL: \\
New York-Northern N.J.-Long Island & Chicago-Gary-Lake County \\
Philadelphia-Wilmington-Trenton & Detroit-Ann Arbor \\
Boston-Lawrence-Salem-Lowell-Brockton & St. Louis-East St. Louis \\
Pittsburgh-Beaver Valley & Cleveland-Akron-Lorain \\
Buffalo-Niagara Falls & Minneapolis-St. Paul \\
& Milwaukee \\
& Cincinnati-Hamilton \\
& Kansas City \\
& \\
SOUTH: & WEST: \\
& \\
Washington, DC & Los Angeles-Anaheim-Riverside \\
Dallas-Fort Worth & San Francisco-Oakland-San Jose \\
Baltimore & Seattle-Tacoma \\
Houston-Galveston-Brazoria & San Diego \\
Atlanta & Portland-Vancouver \\
Miami-Ft. Lauderdale & Honolulu \\
& Anchorage \\
& Denver-Boulder \\
\hline \hline
\end{tabular}

Source: U.S. Bureau of Labor Statistics. The names of these Metropolitan Areas correspond to those established by the U.S. Office of Management and Budget in June 1990.

for the U.S. as a whole and for the 27 Metropolitan Areas listed in Figure 2. In order to obtain an index for the price of recreation goods in terms of other consumption goods, the "Entertainment" index is divided by a weighted average of the indices for "Food plus Beverages", "Housing", and "Transportation", where the weights are 
FIGURE 3-RELATIVE PRICE OF RECREATION GOODS, U.S. AND SELECTED METROPOLITAN AREAS (1982-84=100)

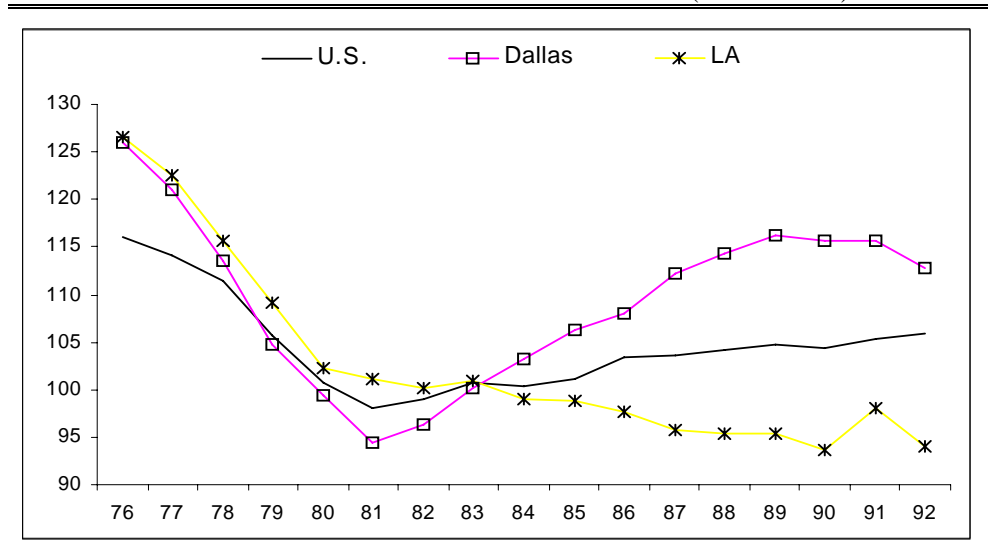

Source: U.S. Bureau of Labor Statistics, CPI-All Urban Consumers. The price indices depicted in this figure are obtained by dividing the "Entertainment" category of the CPI by a weighted average of "Food plus Beverages", "Housing”, and "Transportation". The selected Metropolitan Areas are referred to by the name of their central city.

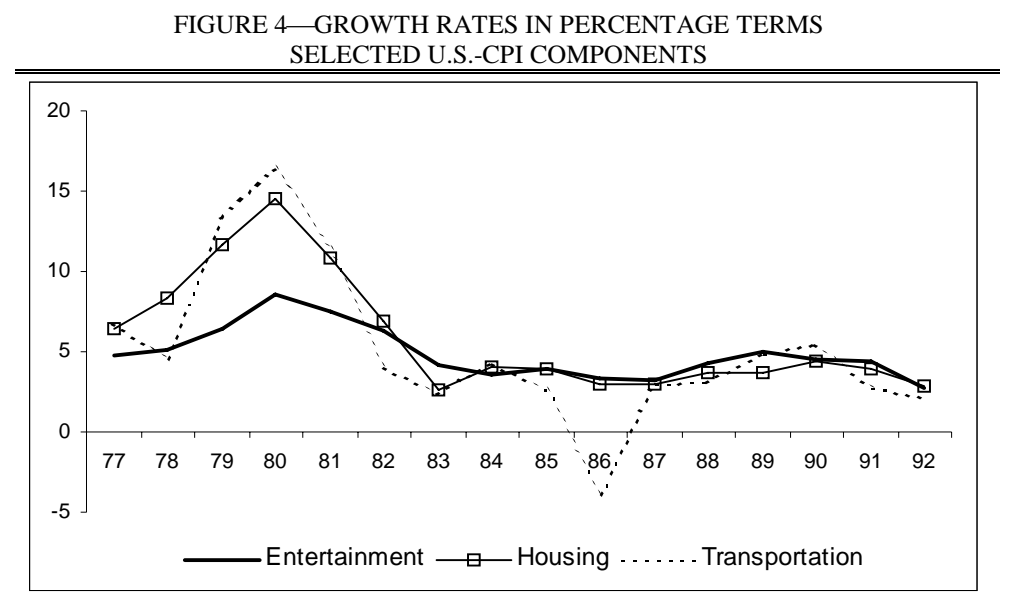

Source: U.S. Bureau of Labor Statistics, CPI-All Urban Consumers.

given by average consumer expenditures on these three groups of items. ${ }^{8}$ To estimate the structural equation derived from Eq. (10), however, the "Entertainment" index is divided by "Food plus Beverages" alone, since $C^{*}$ will be proxied by the food expenditures variable available in the PSID.

Figure 3 shows the evolution of the relative price of recreation goods in the U.S. and selected Metropolitan Areas during the sample period. For the U.S. as a whole,

\footnotetext{
${ }^{8}$ Average consumer expenditures are obtained from the U.S. Consumer Expenditure Survey, Two-Year Report Tables, and may be downloaded at http:/www.bls.gov/cex/csxmsa.htm. Food plus beverages, housing, and transportation absorb approximately two thirds of total consumer expenditures.
} 
the evolution was U-shaped, a pattern that, as Figure 4 shows, was caused by the increases in the price of energy and housing rents that took place in late 1970s, followed by a drop in the price of energy in mid 1980s. ${ }^{9}$ This profile, however, is not exactly matched in all Metropolitan Areas, creating cross-sectional variation in the level of the relative price of recreation goods that, jointly with the time series one, will be utilized to identify the EIS of market time with respect to the price of recreation goods.

\section{Econometric Methodology}

\subsection{Euler Equation for Labor Supply}

Since we purpose to estimate elasticities, we take a log-linear approximation to the intertemporal labor supply function in Eq. (6) around the individual equilibrium. The result of the log-linearization is

$$
\begin{aligned}
\ln N_{i t}^{*}= & \beta_{0}+\beta_{1} \ln P_{i t}+\beta_{2} \ln W_{i t}^{*}+\beta_{3} \ln \psi_{i t}+\beta_{4} \ln \alpha_{i t} \\
& +\beta_{5}\left(\sum_{\kappa=0}^{t-1}\left(\delta-r_{\kappa}\right)\right)+\beta_{5} \ln \lambda_{i},
\end{aligned}
$$

where we made use of the approximations $\ln (1+\delta) \approx \delta$ and $\ln \left(1+r_{t}\right) \approx r_{t}$. The population parameters $\beta_{1}$ and $\beta_{2}$ are the elasticities of intertemporal substitution of market time with respect to the price of recreation goods and the price of leisure time, respectively. Since Eq. (6) was obtained under the assumption of an interior solution, the population under inquiry will be the population of prime-age males. ${ }^{10}$

Each taste-shifter variable $(\psi$ and $\alpha$ ) is approximated by a log-linear function of observed characteristics of the worker, an individual specific term reflecting timeinvariant preferences, and a residual term:

$$
\begin{gathered}
\ln \psi_{i t}=\mathbf{y}_{i t}^{\prime} \boldsymbol{\phi}^{\psi}+y_{i}^{\psi}+\xi_{i t}^{\psi}, \\
\ln \alpha_{i t}=\mathbf{y}_{i t}^{\prime} \boldsymbol{\phi}^{\alpha}+y_{i}^{\alpha}+\xi_{i t}^{\alpha}
\end{gathered}
$$

The vector $\mathbf{y}$ contains time-varying individual variables like age, marital status, family size, number of children, and a disability indicator. It is assumed that $E\left(\xi_{i t}^{\psi}\right)=$ $E\left(\xi_{i t}^{\alpha}\right)=0$, and that the natural logarithm of annual hours of market work is mean independent of $\boldsymbol{\xi}^{\psi}$ and $\boldsymbol{\xi}^{\alpha}$ after having controlled for the observed covariates and the individual heterogeneity. A time trend specific to each Metropolitan Area is included among the explanatory variables in order to control for spatial differences in the

\footnotetext{
${ }^{9}$ The literature discussing the reasons and effects of the oil price shocks includes Hamilton (1983) and Getely, Adelman, and Griffin (1986). Mankiw and Weil (1989) relate the increase in home rental - and ownership - prices to the baby boom.

${ }^{10}$ Indeed, what is studied is the population of prime-age male workers, although given the high participation rates displayed by prime-age males (see Goldin [2000]), it is assumed that both populations display the same behaviour.
} 
market discount rate. The existence of cross-sectional variation in the relative price of recreation goods suggests the presence of this sort of variation in the price of other consumption goods, therefore modifying the real interest rate across Metropolitan Areas.

Answers to questions in which individuals are asked about past labor market outcomes are subject to recall biases. ${ }^{11}$ As a consequence, it is assumed that we have imperfect measures for annual hours of market work and for the price of leisure time, with the corresponding measurement errors following an additive model in which the true measure is uncorrelated with the error term:

$$
\begin{aligned}
& \ln N_{i t}=\ln N_{i t}^{*}+e_{i t}^{N}, \\
& \ln W_{i t}=\ln W_{i t}^{*}+e_{i t}^{W}, \\
& \ln \varpi_{i t}=\ln W_{i t}^{*}+e_{i t}^{\varpi} .
\end{aligned}
$$

Given the definition of the first measure of the price of leisure time, $W$, the errors of measurement $e^{N}$ and $e^{W}$ are quite likely correlated: if labor earnings were objectively reported, ${ }^{12}$ overestimations of the amount of hours worked would lead to underestimations of the price of leisure time and vice versa, causing a negative bias in the estimate of $\beta_{2}$. On the other hand, since the second measure of the price of leisure time, $\varpi$, is obtained from a question separate from those used to construct $N$ and $W$, it is expected that $e^{\varpi}$ is uncorrelated with $e^{N}$ and $e^{W}$, an assumption whose validity we shall test.

The price of recreation goods poses some problems when trying to consistently estimate the effect it exerts over the allocation of time. Firstly, $P_{i t}$ is an unobserved variable and, to approximate it, we make use of price indices at the level of Metropolitan Areas:

$$
\ln P_{i t}=\tau \ln P_{j t}+e_{i t}^{P},
$$

where $j(j=1, . ., 27)$ denotes the Metropolitan Area of residence of individual $i$. As explained in Deaton (1997), in cases like this the measurement error is orthogonal to the error-ridden proxy, and it would seem that we had eluded the attenuation bias. Geronimus, Bound, and Neidert (1996), however, point out that an aggregate variable is usually imperfectly correlated with the microvariable that it is representing, creating an errors-in-variables bias that tends to exert a downward bias on the coefficient of the aggregate proxy. Besides, the aggregate variable may itself be correlated with the residual in the microlevel equation, generating what they call an aggregation bias. This latter sort of statistical endogeneity might arise because of simultaneity bias: the level of prices of recreation goods could be affected by the aggregate number of hours

\footnotetext{
${ }^{11}$ See, among others, Altonji (1986), Juster and Stafford (1991), Bound, Brown, and Mathiowetz (2001), and French (2004).

${ }^{12}$ As seems to be the case, since PSID interviews usually coincide with the income tax time in the U.S.
} 
of leisure time in each Metropolitan Area. In a sense, the amount of hours of leisure time indicates the extent of the market for recreation which, in its turn, determines the division of labor, that is, the variety of recreation activities being offered. This spatial variety of recreation activities could be affecting the evolution of the price of a constant basket of recreation goods measured across Metropolitan Areas by means of price indices.

Secondly, although $P$ stands for the level of the price of recreation goods we have only available relative variations in this level captured by means of price indices. ${ }^{13}$ Nonetheless, notice that

$$
I_{j t}^{P} \equiv \frac{I_{j t}^{X}}{I_{j t}^{C^{*}}} \equiv \frac{\frac{P_{j t}^{X}}{P_{j 0}^{X}}}{\frac{P_{j t}^{C^{*}}}{P_{j 0}^{C^{*}}}},
$$

where $I_{j t}^{P}$ denotes the level of the index of the price of recreation goods in terms of other consumption goods in Metropolitan Area $j$ and period $t, I_{j t}^{X}$ stands for the level of the index of the entertainment component of the CPI, and $I_{j t}^{C^{*}}$ expresses the level of the index of the groups of commodities included in $C^{*}$. By definition, every price index is constructed as the ratio of the level of prices in period $t$ over the level of prices in the base period, indicated with the subindex 0 . Taking natural logarithms on both sides of the previous identity, we obtain

$$
\ln I_{j t}^{P} \equiv\left(\ln P_{j t}^{X}-\ln P_{j t}^{C^{*}}\right)-\left(\ln P_{j 0}^{X}-\ln P_{j 0}^{C^{*}}\right) \equiv \ln P_{j t}-\ln P_{j 0}
$$

Therefore, when we include the log of a price index among the explanatory variables, we are measuring the contemporaneous effect exerted by the price level on the dependent variable plus a time-constant effect representing the influence of the base period prices utilized to construct the index. In our empirical application, this time-constant effect is controlled for by means of Metropolitan Area of residence dummies.

Taking into account all these considerations, the estimating Euler equation for labor supply is

$$
\ln N_{i t}=\beta_{0}+M A_{i t}+\bar{\beta}_{1} \ln P_{j t}+\beta_{2} \ln W_{i t}+\mathbf{y}_{i t}^{\prime} \boldsymbol{\phi}+\beta_{5} t+c_{i}+e_{i t},
$$

where

$$
\begin{gathered}
\bar{\beta}_{1} \equiv \beta_{1} \tau, \\
\phi \equiv\left(\phi^{\psi} \beta_{3}+\phi^{\alpha} \beta_{4}\right), \\
c_{i} \equiv\left(\beta_{5} \ln \lambda_{i}+\beta_{3} y_{i}^{\psi}+\beta_{4} y_{i}^{\alpha}\right), \\
e_{i t} \equiv\left(\beta_{3} \xi_{i t}^{\psi}+\beta_{4} \xi_{i t}^{\alpha}+e_{i t}^{N}+\beta_{1} e_{i t}^{P}-\beta_{2} e_{i t}^{W}\right),
\end{gathered}
$$

\footnotetext{
${ }^{13}$ As it is well known, the indices are, for instance, a hundred in the base year, without necessarily implying that the prices of recreation goods across Metropolitan Areas are the same too.
} 
and $M A_{i t}$ stands for the set of Metropolitan Area dummies. To consistently estimate Eq. (20) we must, at a minimum, eliminate the unobserved heterogeneity, since the marginal utility of wealth is correlated with prices and taste shocks in all time periods. By taking a fixed effects transformation of the data, the estimating equation becomes

$$
\ln \ddot{N}_{i t}=\ddot{M} A_{i t}+\bar{\beta}_{1} \ln \ddot{P}_{j t}+\beta_{2} \ln \ddot{W}_{i t}+\ddot{\mathbf{y}}_{i t}^{\prime} \phi+\beta_{5} \ddot{t}+\ddot{e}_{i t},
$$

where $\ln \ddot{N}_{i t} \equiv \ln N_{i t}-\left(T_{i}^{-1} \sum_{t=1}^{T_{i}} \ln N_{i t}\right), \ln \ddot{P}_{j t} \equiv \ln P_{j t}-\left(T_{i, i \in j}^{-1} \sum_{t=1}^{T_{i, i \in j}} \ln P_{j t}\right)$, and so on, with $T_{i}$ denoting the number of observations available for the randomly sampled $i$ th individual. ${ }^{14}$

Here, ln $\ddot{P}_{j t}$ is possibly endogenous because of the simultaneity bias discussed previously. In order to avoid it, the demeaned population of each Metropolitan Area in each time period is added to Eq. (22) to proxy for the size of the market for recreation. ${ }^{15}$ On the other hand, we can not eliminate the errors-in-variables bias unless $\ln P_{j t}$ is perfectly correlated with $\ln P_{i t}$, and, as a consequence, obtain a consistent estimate of $\beta_{1}$ but of $\bar{\beta}_{1}$. Nonetheless, this bias would be small if the individual's relevant market for recreation goods approaches the Metropolitan Area in which he resides, what could probably be the case given the kind of recreation goods included in the "Entertainment" price index.

"In $\ddot{W}_{i t}$ " is endogenous in Eq. (22) because of the correlation with the measurement error terms $\ddot{e}_{i t}^{W}$ and $\ddot{e}_{i t}^{N}$ included in $\ddot{e}_{i t}$. In order to consistently estimate $\beta_{2}$, we instrument the demeaned first measure of the price of leisure time with two different variables: firstly, a measure of experience in the labor market demeaned and, secondly, the demeaned straight-time hourly wage of those workers paid on an hourly scheme. It could be questioned the exclusion restriction on labor market experience, since the decision to participate in the labor market could be related with unobserved tastes affecting the amount of hours worked. Nevertheless, time invariant tastes have been differenced away, and some time-varying taste controls are included among the explanatory variables in Eq. (22). Besides, Reilly (1994) finds no evidence supporting the inclusion of experience-related variables in the structural equation. We estimate Eq. (22) by a two-step feasible generalized method of moments (GMM) procedure. The assumption of random sampling in the cross-section dimension converts the covariance matrix of the full vector of errors in a block-diagonal matrix. Intra-cluster covariance matrices are left unrestricted.

\footnotetext{
${ }^{14}$ Our panel dataset is unbalanced because of sample attrition and the sample selection criteria discussed in Appendix A. Lillard and Panis (1998) found evidence of significant selectivity in attrition behaviour in the PSID, although Ziliak and Kniesner (1998) showed that nonrandom attrition is of little concern when estimating intertemporal labor supply equations because the effect of attrition is absorbed into fixed effects.

${ }^{15}$ U.S. local area population data is supplied by the Bureau of Economic Analysis. The data can be downloaded at http://www.bea.gov/bea/regional/data.htm
} 


\subsection{Marginal Rate of Substitution Equation for Labor Supply}

Taking a log-linear approximation to Eq. (10) around the individual equilibrium, assuming that the functional forms for taste-shifters and the measures of hours and prices given in the previous subsection are appropriate, and assuming that expenditures in other consumption goods are mismeasured with the measurement error following, again, the additive classical model

$$
\ln C_{i t}=\ln C_{i t}^{*}+e_{i t}^{C},
$$

the estimating Marginal Rate of Substitution equation for labor supply is

$$
\ln N_{i t}=\beta_{0}+M A_{i t}+\bar{\beta}_{1} \ln P_{j t}+\beta_{2} \ln W_{i t}+\beta_{6} \ln C_{i t}+\mathbf{y}_{i t}^{\prime} \phi+a_{i}+b_{i t},
$$

where

$$
\begin{gathered}
a_{i} \equiv\left(\beta_{3} y_{i}^{\psi}+\beta_{4} y_{i}^{\alpha}\right) \\
b_{i t} \equiv\left(\beta_{3} \xi_{i t}^{\psi}+\beta_{4} \xi_{i t}^{\alpha}+e_{i t}^{N}+\beta_{1} e_{i t}^{P}-\beta_{2} e_{i t}^{W}-\beta_{6} e_{i t}^{C}\right),
\end{gathered}
$$

and $\bar{\beta}_{1}$ and $\phi$ were defined previously.

The specification in Eq. (24) is estimated by making use of the annual food expenditures variable available in the PSID. ${ }^{16}$ The unobserved heterogeneity will be proxied by means of time-invariant characteristics of the worker like race and years of schooling completed. The price of leisure time and expenditures in other consumption goods are endogenous in Eq. (24) because of the measurement error terms included in the idiosyncratic error. Although the specification in levels of this estimating equation and the longitudinal nature of the dataset at hand could lead us to think in the estimators suggested by Arellano and Bond (1991) or Arellano and Bover (1995) as suitable ones, the autocorrelated structure of the idiosyncratic error precludes us to utilize estimators based on lags or leads of the explanatory variables. ${ }^{17}$ We should therefore rely on excluded instruments.

We follow Altonji (1986) and instrument the endogenous variables with an individual-specific permanent component of the wage, plus another time-varying individual variable capturing deviations around this profile, both affecting $C_{i t}$ through their effect on $\lambda_{i}$. As in Altonji (1986), the permanent component of the wage is obtained by regressing the straight-time hourly wage on dummy variables for each individual and other controls. ${ }^{18}$ Alternatively, given that years of schooling will be

\footnotetext{
${ }^{16}$ This variable is the sum of food expenditures at home and in restaurants. Even though the survey questions refer only to food expenditures, it is quite likely that reported food expenditures include expenditures in beverages.

${ }^{17}$ The estimated $\operatorname{AR}(1)$ coefficient amounts to 0.46 , robust standard error 0.02 .

${ }^{18}$ In particular, $\varpi$ is regressed on individual, time, and Metropolitan Area of residence dummies, a disability indicator, and human capital controls such as labor market experience squared and the interaction of experience and education.
} 
redundant in the conditional expectation for market hours, we also proxy this permanent component of the wage with the education of each worker. The time-varying variable that captures deviations around the long-run profile of earnings will be, as in Altonji (1986), the straight-time hourly wage itself. We estimate Eq. (24) by a two-step feasible GMM procedure. The covariance matrix of the idiosyncratic errors has the same structure as explained in the previous subsection.

\section{Results}

\subsection{Euler Equation for Labor Supply}

Table 1 presents the main results of estimating the demeaned specification of the Euler equation for labor supply in Eq. (22) by the methods discussed above. The full set of estimates are shown in Table B.1 of Appendix B. In the first column of Table 1 the price of leisure time is instrumented with labor market experience, while in Column (2) it is instrumented with the straight-time hourly wage of those workers paid on an hourly basis, $\varpi$. In order to assess the validity of the instruments by performing a test of overidentifying restrictions, in Column (3) we simultaneously instrument the price of leisure time with both labor market experience and $\varpi$.

The elasticity of intertemporal substitution (EIS) of market time with respect to the price of recreation goods is invariably estimated to be positive, suggesting that a prime-age male puts more market effort during the years in which the price of recreation goods is relatively high. This behavior reflects that the elasticity at which recreation is substituted across periods of time, $\gamma$, is larger than the elasticity at which leisure time and recreation goods are contemporaneously substituted, $\rho$. That is, prime-age males anticipate or delay the enjoyment of recreation more readily than they change the kind of recreation activities consumed. The magnitude of this elasticity varies from column to column depending on the sample size and the magnitude of the estimated EIS with respect to the price of leisure time, but we could say that the range of more reliable estimates centers at 0.18 . Such a magnitude implies that a prime-age male working two thousand hours a year will work three and a half hours more when faced with a one per cent increase in the price of recreation goods. To gauge the size of this effect, notice that the price of recreation goods in terms of other consumption goods dropped in the U.S. around 15 per cent between 1976 and 1981, ${ }^{19}$ suggesting that a prime-age male would have lowered - on average - his market time in 1981 by fifty three hours with regard to the hours worked in 1976. The statistical significance of the EIS of market time with respect to the price of recreation goods reveals the price of recreation goods as a significant determinant of the intertemporal allocation of work effort. As a consequence, we reject the contemporaneous separability between leisure time and recreation goods in the individual's preference ordering

\footnotetext{
${ }^{19}$ See Figure 3.
} 
TABLE 1-EULER EQUATION FOR LABOR SUPPLY

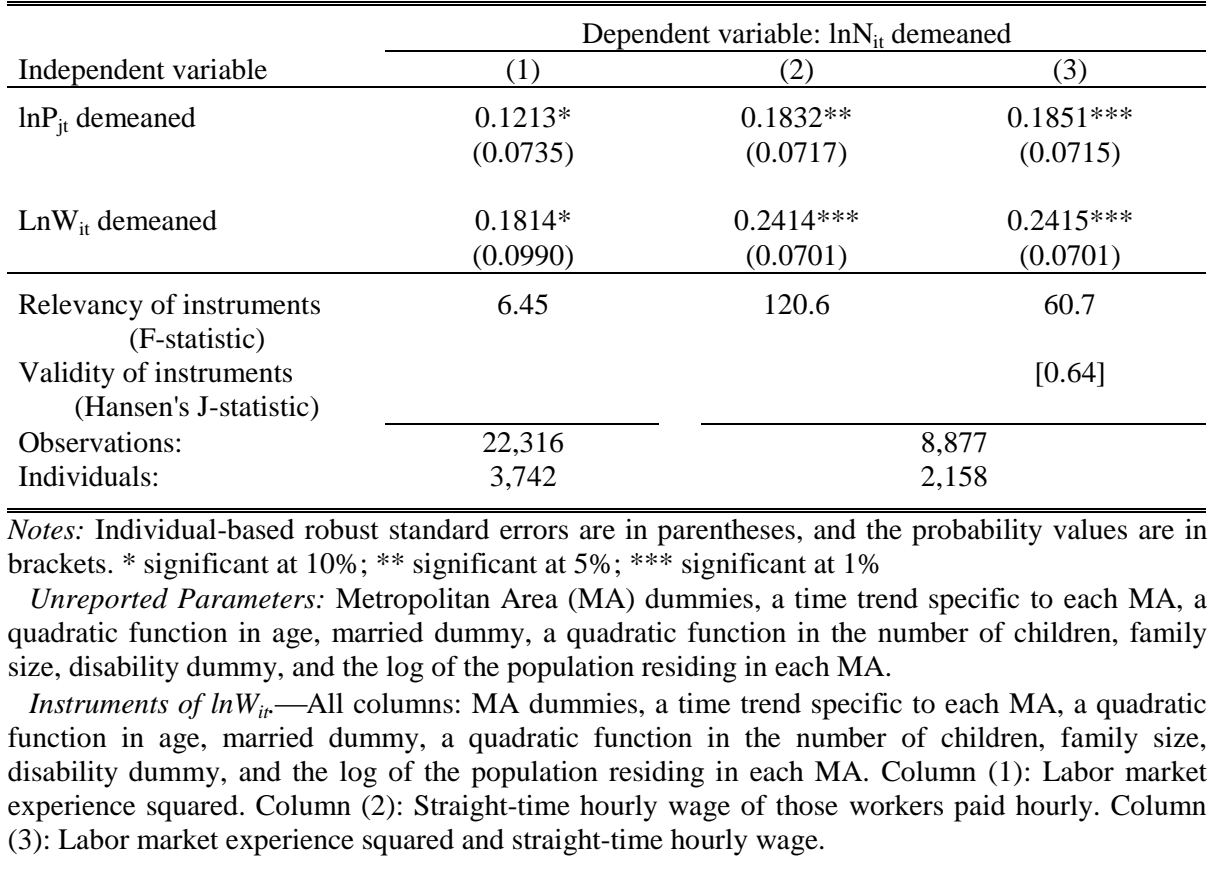

postulated in most of the life-cycle models.

The estimates of the EIS of market time with respect to the price of leisure time are in the range of male wage effects found using PSID data. ${ }^{20}$ Regarding the results reported in Altonji (1986, Tables 1 and 2), our estimated wage effect is lower when $\ln \ddot{W}_{i t}$ is instrumented with labor market experience and higher when instrumented with $\varpi$. The differences are not too important and may be related to the different size of the samples. The estimates reported in this paper are, however, more precise than those reported in Altonji (1986), what is partially a reflection of the good performance of the first-stage equation for $\ln \ddot{W}_{i t}$. ( $R^{2}$ is 0.07 when instrumented with labor market experience, 0.15 when instrumented with $\varpi$, and 0.16 when instrumented with both.) Besides, we do not reject the exogeneity of labor market experience and the straighttime hourly wage as instruments of the price of leisure time: the value of the J-statistic proposed in Hansen (1982) computed after performing the regression in Column (3) amounts to 0.22 (p-value 0.64).

\subsection{Marginal Rate of Substitution Equation for Labor Supply}

Table 2 shows the main results of estimating Eq. (24) by the methods discussed above, while the full set of estimates are shown in Table B.2 of Appendix B. In Column (1)

\footnotetext{
${ }^{20}$ See, among many others, MaCurdy (1981), Altonji (1986), and Ham and Reilly (2002). Mulligan (1999) is an excellent survey for estimates obtained using other datasets.
} 


\begin{tabular}{|c|c|c|c|c|}
\hline \multirow[b]{2}{*}{ Independent variable } & \multicolumn{4}{|c|}{ Dependent variable: $\ln N_{i t}$} \\
\hline & \multicolumn{2}{|c|}{$(1)$} & \multicolumn{2}{|c|}{ (2) } \\
\hline $\ln \mathrm{P}_{\mathrm{jt}}$ & \multirow{3}{*}{\multicolumn{2}{|c|}{$\begin{array}{c}0.1273 \\
(0.0850) \\
0.0765 \\
(0.0522) \\
-0.1454 \\
(0.1511)\end{array}$}} & \\
\hline $\ln W_{i t}$ & & & \\
\hline $\ln C_{i t}$ & & & \multicolumn{2}{|c|}{$\begin{array}{l}-0.1931 \\
(0.1360)\end{array}$} \\
\hline First-stage regressions & Partial $\mathrm{R}^{2}$ & Shea's partial $\mathrm{R}^{2}$ & Partial $\mathrm{R}^{2}$ & Shea's partial $\mathrm{R}^{2}$ \\
\hline $\ln \mathrm{W}_{\mathrm{it}}$ & 0.50 & 0.05 & 0.52 & 0.08 \\
\hline $\operatorname{lnC}_{i t}$ & 0.05 & 0.01 & 0.05 & 0.01 \\
\hline $\begin{array}{l}\text { Validity of instruments } \\
\text { (Hansen's J-statistic) }\end{array}$ & \multicolumn{2}{|c|}{$[0.04]$} & \multicolumn{2}{|c|}{ [0.73] } \\
\hline Observations: & \multicolumn{4}{|c|}{7,506} \\
\hline Individuals: & \multicolumn{4}{|c|}{2,058} \\
\hline \multicolumn{5}{|c|}{$\begin{array}{l}\text { Notes: Individual-based robust standard errors are in parentheses, and the probability values are in } \\
\text { brackets. * significant at } 10 \% \text {; } * * \text { significant at } 5 \% \text {; *** significant at } 1 \% \text {. } \\
\text { Unreported parameters. All columns: intercept, Metropolitan Area (MA) dummies, a quadratic } \\
\text { function in age, married dummy, a quadratic function in the number of children, family size, } \\
\text { disability dummy, race dummy, and the log of the population residing in each MA. Column (1): } \\
\text { years of schooling. } \\
\text { Instruments of } \ln W_{\text {it }} \text { and } \ln C_{i t} \text { - -All columns: intercept, MA dummies, a quadratic function in age, } \\
\text { married dummy, a quadratic function in the number of children, family size, disability dummy, race } \\
\text { dummy, the log of the population residing in each MA, and years of schooling. Column (1): } \\
\text { Individual-specific permanent component of the wage and the straight-time hourly wage. Column } \\
\text { (2): Straight-time hourly wage. }\end{array}$} \\
\hline
\end{tabular}

of Table 2 the price of leisure time and expenditures in other consumption goods are instrumented with the individual-specific permanent component of the wage suggested in Altonji(1986) and $\varpi$. Since years of schooling completed is not statistically different from zero in Eq. (24), ${ }^{21}$ it is utilized as the individual-specific permanent component of the wage in Column (2).

The EIS of market time with respect to the price of recreation goods is estimated to be, again, positive, and of a size similar to those previously obtained. Therefore, irrespective of the specification utilized and of the sample size available, the sign of this elasticity remains the same and its magnitude does not show abrupt variations, increasing our confidence in the results. Moreover, it is again statistically different from zero - at 10 per cent of significance level - in the estimation reported in Column (2). On the other hand, the estimated coefficients associated with the price of leisure time and expenditures in other consumption goods have the sign predicted by the theory and are quite similar in both columns of Table 2. We reject (p-value 0.04) the individual-specific permanent component of the wage suggested in Altonji (1986) as a valid instrument of the price of leisure time and expenditures in other consumption goods. Interestingly enough, the estimated EIS of market time with respect to the price of leisure time reported in Column (2) of Table 2 is remarkably similar to those

\footnotetext{
${ }^{21}$ See Column (2) of Table B.2 in Appendix B
} 
in Altonji (1986, Table 4), even when it is obtained with a different instrument set. ${ }^{22}$

\section{Conclusion}

In this paper we have, firstly, developed an intertemporal substitution model of the labor market in which recreation goods and leisure time are assumed to be non-separable in the individual's preference ordering. Although previous work in intertemporal substitution had usually not rejected the contemporaneous separability between market goods and leisure time, the evidence from static models of choice suggests that changes in the price of some types of goods do influence the allocation of time. Given the importance of leisure time in individuals' time budgets and that recreation activities are relatively time intensive, changes in the price of goods consumed in conjunction with leisure time could strongly influence the allocation of time to different pursuits, including market work. The theoretical model predicts that the elasticity of intertemporal substitution (EIS) of market time with respect to the price of recreation goods may be positive, negative, or even zero, depending crucially on the rate at which recreation is substituted across periods of time and the rate at which leisure time and recreation goods are contemporaneously substituted.

We have then tested the implications of the model by combining individual-level data for the population of U.S. prime-age males with Metropolitan Area-level price indices of recreation goods. The EIS of market time with respect to the price of recreation goods is found to be positive, centered around 0.18 , and statistically different from zero in most estimations, rejecting the contemporaneous separability between leisure time and recreation goods. This result opens multiple research questions, among them: (a) the evidence in Card (1994) points out that prime-age females' EIS of market time with respect to the price of leisure time is usually estimated to be larger than in the case of males, and it would be worth studying whether this different response extends to the elasticity with respect to the price of recreation goods too. (b) Although decisions to participate in the labor market have mostly been related to financial incentives, recreational incentives could likewise contribute to their explanation. (c) In this article the utilization of time has been analyzed integrally, i.e., paying attention to "how time is allocated into separate activities over some relatively long time interval" (Hamermesh [1996]). Thus, we have not cared about the duration of the spells making up of leisure time. If, however, people engage in different recreation activities depending on the duration of the spell of leisure available and these recreation activities were not perfect substitutes, both a modification of the utility function in the lines of Hanoch (1980) and Reilly (1994) and different price indices

\footnotetext{
${ }^{22}$ The low value of the Shea's (1997) partial $R^{2}$ in the first-stage regression for $\ln C$, arises the question of the relevance of the excluded instruments. However, $\varpi$ is statistically different from zero - at the $5 \%$ of significance level - in the first-stage regressions for $\ln W$ and $\ln C$, while years of schooling is statistically significant in the first-stage regression for $\ln W$.
} 
of recreation goods consumed during shorter and longer periods of leisure would be required.

\section{A Data Appendix}

We started downloading data from the PSID for the interview years 1976 to $1993 .^{23}$ There are a total of 53,013 persons, with 26,095 declaring being males. For these, only observations of heads (374,682 person-years lost), present in the household at the moment of the interview (2,117 person-years lost), and with known age (4 personyears lost) were kept. 23,807 observations were dropped because they corresponded to person-years not living in a U.S. Metropolitan Area, and 30,222 observations were deleted because the corresponding person resided in a Metropolitan Area for which price indices were not available. Observations for male heads residing in Miami in 1976 were dropped because the indices needed to construct the price of recreation goods were not available there until 1977 (43 person-years deleted). After these changes, a total of 38,835 observations were available.

Since the question regarding hours of market work refers to the calendar year previous to the year of the interview, we lagged one year most of the variables to consistently assign data to the year in which market time was supplied - a total of 6,049 person-years were deleted. After this change, we applied the following criteria: (1) Only observations of individuals between 25 and 60 years old (person-years lost: $6,979)$. (2) Total annual hours of market work must be positive and no greater than 4,860 (person-years lost: 1,749). (3) Observations for which annual earnings are zero or unknown were dropped (person-years lost: 118). (4) Total annual hours of market work must not rise by more than 250 percent or fall by more than 60 percent from the preceding year, and the absolute change in hours must be less than 3,000 (person-years lost: 751). (5) The real hourly wage, calculated as real annual earnings - in terms of food plus beverages, housing and transportation - divided by total annual hours of market work, must exceed $\$ 0.96$ and be lower than $\$ 600$ - in 1982-84 dollars-, must not rise by more than 250 percent or fall by more than 60 percent from the preceding year, and must not change from the preceding year by more than $\$ 31$ (person-years lost: 692). (6) Observations for which the marital status, the educational attainment, or the disability status of the person were not available, were dropped (person-years lost: 0,143 , and 38, respectively). The surviving sample consists of 3,742 persons and 22,316 person-years. Table A.1 offers a set of descriptive statistics. ${ }^{24}$

\footnotetext{
${ }^{23}$ Some of the data used in this analysis are derived from Sensitive Data Files of the Panel Study of Income Dynamics, obtained under special contractual arrangements designed to protect the anonymity of respondents. These data are not available from the author. Persons interested in obtaining PSID Sensitive Data Files should contact through the Internet at PSIDHelp@isr.umich.edu.

${ }^{24}$ When food expenditures is included among the explanatory variables, criterion (5) is applied over a real hourly wage calculated in terms of food plus beverages only (person-years lost: 690), criterion (6) is complemented by dropping observations with invalid codification for race (person-
} 
TABLE A.1-DESCRIPTIVE STATISTICS

Individuals: 3,742

\begin{tabular}{cccc} 
& \multicolumn{2}{c}{ Average obs. per individual: 6.0} & Std. dev. \\
\hline Variable & Obs. & Mean & 590.1 \\
$\mathrm{~N}$ & 22,316 & 2,140 & 9.000 \\
$\mathrm{~W}$ & 22,316 & 13.18 & 9.354 \\
$\mathbf{w}$ & 8,877 & 10.13 & 2,219 \\
$\mathrm{C}$ & 18,808 & 4,602 & 9.604 \\
Age & 22,316 & 37.80 & 2.856 \\
Education & 22,316 & 13.21 & 10.37 \\
Experience & 22,316 & 19.60 & 1.300 \\
No. Children & 22,316 & 1.216 & 1.652 \\
Family size & 22,316 & 3.343 & 0.482 \\
Nonwhite & 22,316 & 0.366 & 0.371 \\
Married & 22,316 & 0.835 & 0.266 \\
Disabled & 22,316 & 0.076 &
\end{tabular}

Notes. - N : Annual hours worked in the main job, secondary job/s, and overtime. $W$ : First measure of the price of leisure time, obtained as annual earnings in 1982-84 dollars divided by annual hours worked. $\varpi$. Second measure of the price of leisure time: straight-time hourly wage in 1982-84 dollars, asked of those workers who are paid on an hourly basis. $C$ : Annual food expenditures at home and in restaurants in 1982-84 dollars. Age: in years. Education: Highest grade finished; a code 17 indicates some post-graduate work. Experience: Years of labor market experience, calculated as age minus years of schooling minus five. No. Children: Number of persons in the family unit under 18 years old. Nonwhite, Married, and Disabled: binary indicators taking on value 1 when the individual declares to be non-white, is legally married or permanently cohabiting, or has any physical or nervous condition that limits the type of work or the amount of work he can do, respectively.

\section{B Complete Estimation Results}

This appendix provides the full set of estimates of Eqs. (22) and (24). The common set of time-varying taste controls included in both specifications is made up of a quadratic function of age, a married dummy, a quadratic function of the number of children, family size, a disability dummy, and the log of the population of each Metropolitan Area in each time period. ${ }^{25}$ When labor market experience is utilized to instrument the price of leisure time, it is raised to the square to avoid a perfect collinearity with age and the intercept, since it is calculated as age minus years of schooling minus five. Time dummies are not included among the explanatory variables because Metropolitan Area and time dummies alone are able to explain 62 per cent of the total variation in the price of recreation goods, leaving, as a consequence, little variation to be exploited in the estimation of its effect on annual hours worked. Since Metropolitan Area dummies must be included, we control for tastes for work by means of the relatively rich specification of taste-shifters considered in Eqs. (22)

years lost: 80), and an additional sample selection criterion is that real food expenditures must not rise by more than 250 percent or fall by more than 60 percent from the preceding year, and it must not be missing or zero (person-years lost: 3,430 ). The surviving sample contains 3,651 persons and 18,808 person-years.

${ }^{25}$ For definitions of these variables, see the notes to Table A.1. 
TABLE B.1-EULER EQUATION FOR LABOR SUPPLY

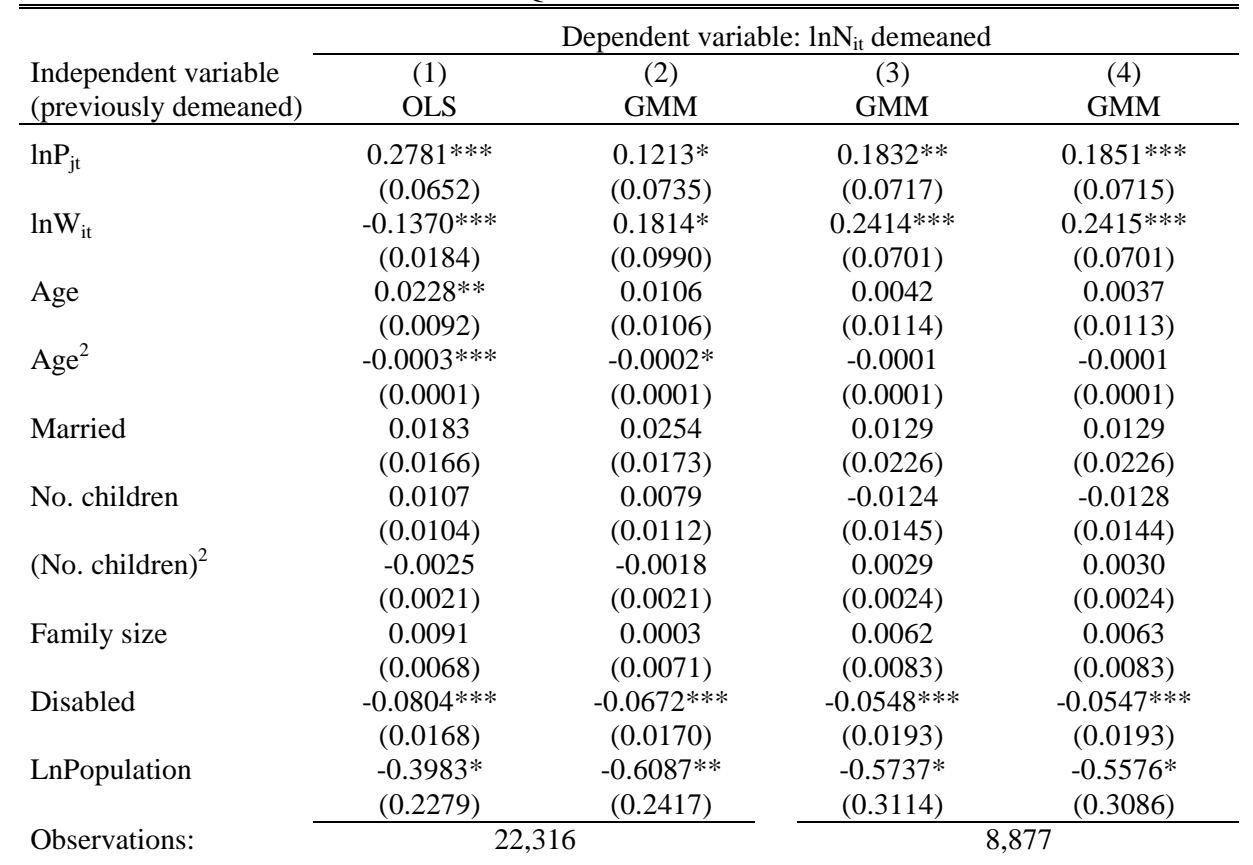

Notes: Individual-based robust standard errors in parentheses. ${ }^{*}$ significant at $10 \%$; ${ }^{* *}$ significant at $5 \%$; *** significant at $1 \%$.

Unreported Parameters: Metropolitan Area (MA) dummies and a time trend specific to each MA.

Instruments of $\ln W_{i t}$ - - Columns (2) to (4): Reported independent variables, MA dummies, and a time trend specific to each MA. Column (2): Labor market experience squared. Column (3): Straighttime hourly wage of those workers paid hourly. Column (4): Labor market experience squared and straight-time hourly wage.

and (24).

Table B.1 presents the complete results of estimating Eq. (22). To control for potential differences between the subjective and market discount rates, all regressions include a time trend specific to each Metropolitan Area. For comparative reasons, the first column of Table B.1 exhibits the results of a simple Pooled OLS estimation. Although the unobserved heterogeneity has been differenced away, the sign of the estimated EIS of market time with respect to the price of leisure time is not the theoretically expected. Columns (2) to (4) show the output of the GMM estimations. We do not see significant demographic effects, with the exception of the disability binary indicator: on average, a disabled prime-age male works 6 per cent less hours in the market. Interestingly enough, the size of the population influences the allocation of time: prime-age males work less when residing in more populated Metropolitan Areas, possibly because of the larger set of recreational activities available.

The complete estimation results of Eq. (24) are displayed in Table B.2. The food expenditures measure available in the PSID was not asked in the interview years 1988 and 1989, and thus we can not utilize the observations corresponding to those years. The first column of Table B.2 shows the output of a simple Pooled OLS 
TABLE B.2-MARGINAL RATE OF SUBSTITUTION EQUATION FOR LABOR SUPPLY

\begin{tabular}{|c|c|c|c|}
\hline \multirow{2}{*}{ Independent variable } & \multicolumn{3}{|c|}{ Dependent variable: $\ln \mathrm{N}_{\mathrm{it}}$} \\
\hline & $\begin{array}{l}\text { (1) } \\
\text { OLS }\end{array}$ & $\begin{array}{c}(2) \\
\text { GMM }\end{array}$ & $\begin{array}{c}\text { (3) } \\
\text { GMM }\end{array}$ \\
\hline $\ln \mathrm{P}_{\mathrm{jt}}$ & $\begin{array}{c}0.0673 \\
(0.0709)\end{array}$ & $\begin{array}{c}0.1273 \\
(0.0850)\end{array}$ & $\begin{array}{l}0.1417 * \\
(0.0837)\end{array}$ \\
\hline $\operatorname{LnW}_{\text {it }}$ & $\begin{array}{c}-0.0502 * * * \\
(0.0158)\end{array}$ & $\begin{array}{c}0.0765 \\
(0.0522)\end{array}$ & $\begin{array}{c}0.0969 * * \\
(0.0445)\end{array}$ \\
\hline $\ln C_{i t}$ & $\begin{array}{c}0.0972^{* * *} \\
(0.0129)\end{array}$ & $\begin{array}{l}-0.1454 \\
(0.1511)\end{array}$ & $\begin{array}{l}-0.1931 \\
(0.1360)\end{array}$ \\
\hline Age & $\begin{array}{c}0.0060 \\
(0.0045)\end{array}$ & $\begin{array}{c}0.0134^{* *} \\
(0.0065)\end{array}$ & $\begin{array}{c}0.0132 * * \\
(0.0061)\end{array}$ \\
\hline $\mathrm{Age}^{2}$ & $\begin{array}{c}-0.0001 \\
(0.0001)\end{array}$ & $\begin{array}{c}-0.0002^{* *} \\
(0.0001)\end{array}$ & $\begin{array}{c}-0.0002 * * \\
(0.0001)\end{array}$ \\
\hline Married & $\begin{array}{c}0.0460 * * * \\
(0.0150)\end{array}$ & $\begin{array}{c}0.0671 * * * \\
(0.0253)\end{array}$ & $\begin{array}{c}0.0753 * * * \\
(0.0241)\end{array}$ \\
\hline No. children & $\begin{array}{c}0.0133 \\
(0.0090)\end{array}$ & $\begin{array}{l}-0.0027 \\
(0.0114)\end{array}$ & $\begin{array}{l}-0.0025 \\
(0.0113)\end{array}$ \\
\hline$(\text { No. children })^{2}$ & $\begin{array}{l}-0.0018 \\
(0.0013)\end{array}$ & $\begin{array}{l}-0.0020 \\
(0.0016)\end{array}$ & $\begin{array}{l}-0.0025 \\
(0.0016)\end{array}$ \\
\hline Family size & $\begin{array}{l}-0.0094 \\
(0.0059)\end{array}$ & $\begin{array}{c}0.0248 \\
(0.0208)\end{array}$ & $\begin{array}{c}0.0309 \\
(0.0190)\end{array}$ \\
\hline Disabled & $\begin{array}{c}-0.1107 * * * \\
(0.0204)\end{array}$ & $\begin{array}{c}-0.1027 * * * \\
(0.0208)\end{array}$ & $\begin{array}{c}-0.1019 * * * \\
(0.0207)\end{array}$ \\
\hline Nonwhite & $\begin{array}{c}-0.0222^{* *} \\
(0.0102)\end{array}$ & $\begin{array}{c}-0.0464^{* *} \\
(0.0206)\end{array}$ & $\begin{array}{c}-0.0498 * * \\
(0.0195)\end{array}$ \\
\hline Education & $\begin{array}{c}0.0059 * * \\
(0.0023)\end{array}$ & $\begin{array}{c}0.0015 \\
(0.0026)\end{array}$ & \\
\hline LnPopulation & $\begin{array}{c}0.0744 \\
(0.0494)\end{array}$ & $\begin{array}{c}-0.0202 \\
(0.0847)\end{array}$ & $\begin{array}{c}-0.0350 \\
(0.0815)\end{array}$ \\
\hline Intercept & $\begin{array}{c}6.0585^{* * *} \\
(0.4480) \\
\end{array}$ & $\begin{array}{c}7.8150 * * * \\
(1.2934) \\
\end{array}$ & $\begin{array}{c}8.1809 * * * \\
(1.1984)\end{array}$ \\
\hline Observations & & 7,506 & \\
\hline \multicolumn{4}{|c|}{$\begin{array}{l}\text { Notes: Individual-based robust standard errors in parentheses. }{ }^{*} \text { significant at } 10 \% \text {; }{ }^{* *} \text { significant at } \\
5 \% \text {; *** significant at } 1 \% \text {. } \\
\text { Unreported parameters: Metropolitan Area (MA) dummies. } \\
\text { Instruments of } \ln W_{i t} \text { and } \ln C_{i t} \text { - Columns (2) and (3): Reported independent variables and MA } \\
\text { dummies. Column (2): Individual-specific permanent component of the wage and the straight-time } \\
\text { hourly wage asked of those workers paid on an hourly basis. Column (3): Years of schooling and the } \\
\text { straight-time hourly wage. }\end{array}$} \\
\hline
\end{tabular}

estimation. The sign of the estimated coefficients associated to the price of leisure time and expenditures in other consumption goods are not those theoretically expected. Columns (2) and (3) report the output of the GMM estimations. We observe that the age and marital status of the individual are now significant explanatory variables, and that, on the contrary, the population of each Metropolitan Area has become irrelevant. The different nature of the confounding factors controlled by $\lambda$ - time-constant - and $C$-time-varying - seems to be the reason for these changes. As before, however, the disability status of the individual exerts a non-trivial influence on the allocation of time. Besides, the race binary indicator is statistically different from zero: a nonwhite individual works, on average, five per cent less hours in the market than a white male of similar characteristics. 


\section{The Model with Uncertainty}

An individual at age $t$ solves

$$
V\left(A_{t}, t\right)=\max _{\left\{C_{t}^{*}, X_{t}, L_{t}, A_{t+1}\right\}}\left\{\begin{array}{c}
\frac{C_{t}^{* 1-\frac{1}{\theta}}-1}{1-\frac{1}{\theta}}+\psi_{t}\left[\frac{1}{1-\frac{1}{\gamma}}\left(X_{t}^{1-\frac{1}{\rho}}+\alpha_{t} L_{t}^{1-\frac{1}{\rho}}\right)^{\frac{1-\frac{1}{\gamma}}{1-\frac{1}{\rho}}}\right]+ \\
+\frac{1}{(1+\delta)} E_{t} V\left(A_{t+1}, t+1\right)
\end{array}\right\}
$$

subject to

$$
A_{t+1}=\left(1+r_{t}\right) A_{t}+W_{t}^{*}\left(1-L_{t}\right)-C_{t}^{*}-P_{t} X_{t}
$$

and

$$
C_{t}^{*}, X_{t}, L_{t} \geq 0
$$

where $V\left(A_{t}, t\right)$ represents the maximum attainable utility from period $t$ on given initial resources $A_{t}$, and $E_{t}$ stands for the expectational operator taken with all the information available at time $t$. Assuming an interior optimum, the optimality conditions are given by the budget constraint in Eq. (C.1.2) and the next set of first order conditions:

$$
\begin{aligned}
C_{t}^{* \frac{-1}{\theta}} & =\lambda_{t}, \\
\psi_{t} \Omega_{t} X_{t}^{\frac{-1}{\rho}} & =\lambda_{t} P_{t}, \\
\psi_{t} \Omega_{t} \alpha_{t} L_{t}^{\frac{-1}{\rho}} & =\lambda_{t} W_{t}^{*}, \\
\frac{1}{(1+\delta)} E_{t}\left\{\lambda_{t+1}\left(1+r_{t+1}\right)\right\} & =\lambda_{t},
\end{aligned}
$$

where $\Omega_{t}$ was defined in Eq. (4), $\lambda_{t}$ is the marginal utility of period $t$ wealth, and in the intertemporal optimality condition (Eq. [C.2.4]) we made use of the Envelope Theorem. The marginal utility of wealth, which is constant in a perfect foresight model, is now steadily updated as new information becomes available to the individual, who tries to equalize the suitably discounted marginal utilities of wealth across periods of time.

The intertemporal labor supply function is ${ }^{26}$

$$
N_{t}^{*}=1-\psi_{t}^{\gamma}\left(\frac{W_{t}^{*}}{\alpha_{t}}\right)^{-\rho}\left(P_{t}^{1-\rho}+\alpha_{t}^{\rho} W_{t}^{* 1-\rho}\right)^{\frac{\rho-\gamma}{1-\rho}} \lambda_{t}^{-\gamma} .
$$

By taking a log-linear approximation to Eq. (C.3) around the individual equilibrium, we obtain

$$
\ln N_{i t}^{*}=\beta_{0}+\beta_{1} \ln P_{i t}+\beta_{2} \ln W_{i t}^{*}+\beta_{3} \ln \psi_{i t}+\beta_{4} \ln \alpha_{i t}+\beta_{5} \ln \lambda_{i t},
$$

\footnotetext{
${ }^{26}$ We consider in detail the specification and estimation of the Euler equation for labor supply since the Marginal Rate of Substitution equation remains exactly the same as in the case of perfect certainty.
} 
while by assuming that the functional forms for taste-shifters and measures of hours and prices given in the main text are appropriate, the alternative estimating equation becomes

$$
\ln N_{i t}=\beta_{0}+M A_{i t}+\bar{\beta}_{1} \ln P_{j t}+\beta_{2} \ln W_{i t}+\mathbf{y}_{i t}^{\prime} \boldsymbol{\phi}+\beta_{5} \ln \lambda_{i t}+a_{i}+e_{i t}
$$

$\bar{\beta}_{1}, \phi, a_{i}$, and $e_{i t}$ where defined in the main text, and $M A_{i t}$ stands for the set of Metropolitan Area of residence dummies. Taking a first-differences transformation within the observations belonging to the same individual and using Eq. (C.2.4) to eliminate $\ln \lambda_{i t}-\ln \lambda_{i(t-1)},{ }^{27}$ we obtain

$$
\begin{aligned}
D \ln N_{i t}= & D M A_{i t}+\bar{\beta}_{1} D \ln P_{j t}+\beta_{2} D \ln W_{i t}+D \mathbf{y}_{i t}^{\prime} \boldsymbol{\phi} \\
& +\beta_{5}\left(\delta-r_{t}\right)+D e_{i t}+u_{i t},
\end{aligned}
$$

where $D$ represents the first-differences operator and $u_{i t}$ is a forecast error correlated with contemporaneous regressors but orthogonal to information dated previously if individuals have rational expectations. As a consequence, all variables contemporaneously dated with the forecast error need to be instrumented. We follow Arellano and Bond (1991) and instrument $D \ln P_{j t}$ with suitable lags of $\ln P_{j} .{ }^{28}$ However, since we detect $\operatorname{AR}(1)$ serial correlation in the idiosyncratic error of Eq. (C.5), $D \ln W_{i t}$ is instrumented with, on one hand, the first differences in labor market experience and, on the other hand, the first differences of the straight-time hourly wage of those workers paid hourly, $\varpi$.

The results of estimating Eq. (C.6) by the difference GMM estimator of Arellano and Bond (1991) are given in Table C.1. In Column (1) the price of leisure time is instrumented with labor market experience squared, while in Column (2) $\varpi$ is the instrument utilized. The estimated EIS of market time with respect to the price of recreation goods is, again, positive, and statistically different from zero in Column (2), rejecting the separability between leisure time and recreation goods in the individual's preference ordering. The EIS of market time with respect to the price of leisure time is more tightly estimated than in Table 1, and the point estimates are remarkably similar to those in Altonji (1986, Table 1).

\footnotetext{
${ }^{27}$ See Altonji (1986).

${ }^{28}$ We utilize all available lags of $\ln P$ dated $t-2$ or earlier.
} 


\begin{tabular}{lcc}
\hline \hline & \multicolumn{2}{c}{ Dependent variable: first-differenced $\operatorname{lnN}_{\mathrm{it}}$} \\
\cline { 2 - 3 } $\begin{array}{l}\text { Independent variable } \\
\text { (first-differenced) }\end{array}$ & $(1)$ & $(2)$ \\
\hline \multirow{2}{*}{$\ln _{\mathrm{jt}}$} & 0.0999 & $0.2555^{* * *}$ \\
& $(0.0645)$ & $(0.0943)$ \\
$\ln \mathrm{W}_{\mathrm{it}}$ & 0.0879 & 0.0803 \\
& $(0.0576)$ & $(0.0528)$ \\
\hline \multirow{2}{*}{ Hansen's J-statistic } & {$[0.39]$} & {$[0.19]$} \\
\cline { 2 - 3 } Observations: & 17,587 & 5,899 \\
Individuals: & 2,971 & 1,397 \\
\hline
\end{tabular}

Notes: Individual-based robust standard errors are in parentheses, and the probability values are in brackets. * significant at $10 \%$; ** significant at $5 \%$; *** significant at $1 \%$

Unreported Parameters: Metropolitan Area (MA) dummies, a time trend specific to each $\mathrm{MA}$, a quadratic function in age, married dummy, a quadratic function in the number of children, family size, disability dummy, and the log of the population residing in each MA. Instruments of $\ln P_{j t}$ and $\ln W_{i t}$ - - All columns: MA dummies, a time trend specific to each MA, a quadratic function in age, married dummy, a quadratic function in the number of children, family size, disability dummy, the log of the population residing in each MA, and lags of $\ln \mathrm{P}$ dated (t-2) or earlier. Column (1): Labor market experience squared. Column (2): Straight-time hourly wage of those workers paid hourly.

\section{References}

[1] Abbott, Michael and Orley Ashenfelter (1976): "Labour Supply, Commodity Demand and the Allocation of Time", The Review of Economic Studies, Vol. 43, No. 3, pp. 389-411.

[2] Altonji, Joseph G. (1986): "Intertemporal Substitution in Labor Supply: Evidence from Micro Data", Journal of Political Economy, Vol. 94, No. 3, pt. 2, pp. S176-S215.

[3] Altonji, Joseph G. and John C. Ham (1990): "Intertemporal Substitution, Exogeneity, and Surprises: Estimating Life Cycle Models for Canada", Canadian Journal of Economics, Vol. XXIII, No. 1, pp. 1-43.

[4] Arellano, Manuel and Stephen Bond (1991): "Some Tests of Specification for Panel Data: Monte Carlo Evidence and an Application to Employment Equations", The Review of Economic Studies, Vol. 58, No. 2, pp. 277-297.

[5] Arellano, Manuel and Olympia Bover (1995): "Another Look at the Instrumental Variable Estimation of Error-Components Models", Journal of Econometrics, Vol. 68, pp. 29-51.

[6] Auerbach, Alan J. and Laurence J. Kotlikoff (1987): Dynamic Fiscal Policy, Cambridge University Press. 
[7] Blundell, Richard and Thomas E. MaCurdy (1999): "Labor Supply: A Review of Alternative Approaches"; in Ashenfelter, Orley and David Card (Eds.): Handbook of Labor Economics, Elsevier Science B. V.

[8] Bound, John, Charles Brown, and Nancy Mathiowetz (2001): "Measurement Error in Survey Data", in J. Heckman and E. Leamer (Eds.), Handbook of Econometrics, Vol. 5 (North-Holland).

[9] Browning, Martin, Angus Deaton, and Margaret Irish (1985): "A Profitable Approach to Labor Supply and Commodity Demands Over the Life-Cycle", Econometrica, Vol. 53, No. 3, pp. 503-543.

[10] Browning, Martin and Costas Meghir (1991): "The Effects of Male and Female Labor Supply on Commodity Demands", Econometrica, Vol. 59, No. 4, pp. 925951.

[11] Card, David E. (1994): "Intertemporal Labor Supply: An Assessment"; in Sims, Christopher A. (Ed.), Advances in Econometrics, Sixth World Congress, Cambridge, Cambridge University Press.

[12] Deaton, Angus (1997): The Analysis of Household Surveys: a Microeconometric Approach to Development Policy, The World Bank, Washington, D.C.

[13] French, Eric (2004): "The Labor Supply Response to (Mismeasured but) Predictable Wage Changes", The Review of Economics and Statistics, Vol. 86, No. 2, pp. 602-613.

[14] Geronimus, Arline T., John Bound, and Lisa J. Neidert (1996): “On the Validity of Using Census Geocode Characteristics to Proxy Individual Socioeconomic Characteristics", Journal of the American Statistical Association, Vol. 91, No. 434, pp. 529-537.

[15] Getely, Dermont, M.A. Adelman, and James M. Griffin (1986): "Lessons from the 1986 Oil Price Collapse", Brookings Papers on Economic Activity, Vol. 1986, No. 2, pp. 237-284.

[16] Ghez, Gilbert R. and Gary S. Becker (1975): The Allocation of Time and Goods Over the Life-Cycle, NBER, New York.

[17] Goldin, Claudia (2000): "Labor Markets in the Twentieth Century"; in Engerman, Stanley L. and Robert E. Gallman (Eds.): The Cambridge History of the United States, Vol. III (Cambridge University Press), pp. 549-624.

[18] Gronau, Reuben and Daniel S. Hamermesh (2003): "Time vs. Goods: The Value of Measuring Household Production Technologies", NBER, w9650. 
[19] Ham, John C. and Kevin T. Reilly (2002): "Testing Intertemporal Substitution, Implicit Contracts, and Hours Restriction Models of the Labor Market Using Micro Data", The American Economic Review, Vol. 92, No. 4, pp. 905-927.

[20] Hamermesh, Daniel S. (1996): Workdays, Workhours, Work Schedules: Evidence for the United States and Germany, Kalamazoo, MI: The W. E. Upjohn Institute.

[21] Hamermesh, Daniel S., Harley Frazis, and Jay Stewart (forthcoming): "Data Watch - The American Time Use Survey", Journal of Economic Perspectives.

[22] Hamilton, James D. (1983): "Oil and the Macroeconomy since World War II", The Journal of Political Economy, Vol. 91, No. 2, pp. 228-248.

[23] Hanoch, Giora (1980): "Hours and Weeks in the Theory of Labor Supply", in Smith, James P. (Ed.): Female Labor Supply, Princeton NJ: Princeton University Press, pp. 119-165.

[24] Hansen, Lars P. (1982): "Large Sample Properties of Generalized Method of Moments Estimators", Econometrica, Vol. 50, No. 3, pp. 1029-1054.

[25] Juster, Thomas F. and Frank P. Stafford (1991): "The Allocation of Time: Empirical Findings, Behavioural Models, and Problems of Measurement", Journal of Economic Literature, Vol. XXIX, June, pp. 471-522.

[26] Lillard, Lee A. and Constantijn Panis (1998): "Panel Attrition from the Panel Study of Income Dynamics", Journal of Human Resources, Vol. 33, Iss. 2, pp. 437-457.

[27] MaCurdy, Thomas E. (1981): “An Empirical Model of Labor Supply in a LifeCycle Setting", Journal of Political Economy, Vol. 89, No. 6, pp. 1059-1085.

[28] Mankiw, N. Gregory, Julio J. Rotemberg, and Lawrence H. Summers (1985): "Intertemporal Substitution in Macroeconomics", The Quarterly Journal of Economics, Vol. 100, No. 1, pp. 225-251.

[29] Mankiw, N. Gregory and David N. Weil (1989): "The Baby Boom, the Baby Bust, and the Housing Market", Regional Science and Urban Economics, Vol. 19, No. 2, pp. 235-258.

[30] Mulligan, Casey B. (1999): "Substitution over Time: Another Look at Life Cycle Labor Supply", NBER Macroeconomics Annual 1998, Vol. 13, Cambridge: MIT Press.

[31] Nelson, Jon P. (2001): "Hard at Play! The Growth of Recreation in Consumer Budgets, 1959-1998", Eastern Economic Journal, Vol. 27, No. 1, pp. 35-53. 
[32] Reilly, Kevin T. (1994): “Annual Hours and Weeks in a Life-Cycle Labor Supply Model: Canadian Evidence on Male Behavior", Journal of Labor Economics, Vol. 12, No. 3, pp. 460-477.

[33] Shea, John (1997): "Instrument Relevance in Multivariate Linear Models: A Simple Measure", The Review of Economics and Statistics, Vol. 79, No. 2, pp. 348-352.

[34] Ziliak, James P. and Thomas J. Kniesner (1998): "The Importance of Sample Attrition in Life Cycle Labor Supply Estimation", Journal of Human Resources, Vol. 33, Iss. 2, pp. 507-530. 